\title{
ANALISIS KUALITAS PRODUK KONVEKSI BERUPA SERAGAM SEKOLAH DENGAN MENGGUNAKAN METODE SIX SIGMA DI TEMPAT PRAKTIK KETERAMPILAN USAHA (TPKU) BIDANG KONVEKSI TEBUIRENG
}

\author{
Ahmad Al Amin \\ Teknik Industri, Fakultas Teknik, Universitas Hasyim Asy’ari, Email : alamien02j@gmail.com \\ Sumarsono \\ Teknik Industri, Fakultas Teknik, Universitas Hasyim Asy’ari, Email : sonsumarsono13@gmail.com \\ Nur Kholis \\ Teknik Elektro, Fakultas Teknik, Universitas Hasyim Asy’ari, Email : nurkholis.unhasy@yahoo.com
}

\section{Abstrak}

Cepatnya laju pertumbuhan teknologi dan informasi di era modern sekarang ini, mendorong perusahaan untuk lebih mengembangkan pemikiran dan pandangannya guna memaksimalkan sasaran dan tujuan yang telah ditetapkan. Tempat Praktik Keterampilan Usaha (TPKU), merupakan usaha yang bergerak di bidang konveksi yang dikelola oleh Pesantren Tebuireng. Salah satu produk konveksi yang paling banyak diproduksi adalah seragam sekolah. Dalam memproduksi seragam sekolah, konveksi juga berusaha untuk terus meningkatkan kualitas dengan menekan angka kecacatan pada produk. Beberapa hal yang perlu dilakukan adalah mengidentifikasi faktor penyebab cacat menggunakan metode six sigma, menghitung nilai sigma kualitas, serta memberikan usulan tindakan yang tepat untuk pengendalian kualitas seragam sekolah. Six sigma adalah suatu alat peningkatan kualitas menuju target 3,4 kegagalan per sejuta kesempatan untuk setiap hasil produksi. Jadi six sigma merupakan salah satu metode baru dalam bidang manajemen kualitas yang bertujuan untuk pengendalian dan peningkatan kualitas. Dengan menggunakan metode six sigma, dapat diketahui bahwa ada tujuh jenis penyebab cacat (CTQ) yang terjadi pada produk seragam sekolah. Dua jenis penyebab cacat yang paling dominan sering terjadi adalah: jahitan tidak rapi dengan persentase sebesar 51,1\% dan noda pada seragam sebesar $28,4 \%$. Untuk kualitas seragam sekolah yang dihasilkan oleh Konveksi Tebuireng masih rendah yaitu 2,95 sigma dengan tingkat kecacatan produk sebanyak 74.830 produk dalam sejuta produk (DPMO). Dari penerapan six sigma ini pula, dapat disimpulkan bahawa usulan tindakan yang harus dilakukan konveksi untuk mengurangi tingkat kecacatan produk adalah dengan memfokuskan pengawasannya pada perbaikan kinerja karyawan, kinerja mesin, standar kerja yang berlaku, sarana dan prasarana yang ada, memberikan motivasi dalam bekerja, serta memperbaiki manajemen waktu dengan baik.

Kata Kunci: Six Sigma, Pengendalian Kualitas, CTQ, DPMO

\section{Abstract}

The rapid rate of growth of technology and information in the modern era today, encourages companies to further develop their thoughts and views to maximize the goals and objectives set. The Place to Practice Business Skills (TPKU), is a business engaged in the field of convection managed by Tebuireng Boarding School. One of the most widely used convection products is the school uniform. In producing school uniforms, convection also strives to continuously improve quality by pressing the number of defects in the product. Some things that need to be done are identifying the factors that cause disability using the Six Sigma method, calculate the quality of sigma, and propose appropriate actions to control the quality of school uniforms. Six sigma is a tool of quality improvement toward the 3,4 target of failure per a million opportunities for each production. So six sigma is one of the new methods in the field of quality management aimed at quality control and improvement. By using the six sigma method, it can be seen that there are seven types of defects (CTQ) that occur in school uniform products. The two most common types of defects are: seams that are not tidy with a percentage of $51.1 \%$ and stain on uniform of $28.4 \%$. For the quality of school uniforms produced by Tebuireng Convection is still low ie 2.95 sigma with a product defect rate as much 74830 products in one million products (DPMO). From the application of these six sigma, it can be concluded that the proposed action to be done convection to reduce the level of product defects is to focus its supervision on improving employee performance, engine performance, applicable work standards, existing facilities and infrastructure, provide motivation to work, and improve time management well.

Keywords: Six Sigma, Pengendalian Kualitas, CTQ, DPMO 


\section{PENDAHULUAN}

Laju perkembangan teknologi dan informasi yang bergerak cepat, mengakibatkan perubahan pola pikir oleh para pelaku produksi. Mereka dituntut untuk menghasilkan produk dengan kualitas yang baik. Hal ini diperlukan akibat dari semakin ketatnya persaingan pasar sampai di tingkat internasioal. Menurut (Roy Putra,2016:12) kualitas yang baik dilihat dari sudut pandang konsumen adalah apabila produk yang dibeli sesuai dengan keinginan, memiliki manfaat yang sesuai dengan kebutuhan, dan setara dengan pengorbanan yang dikeluarkan oleh kunsumen.

TPKU Pesantren Tebuireng, merupakan Tempat Praktik Keterampilan Usaha di bidang konveksi yang memproduksi pakaian seragam sekolah, dll. Dimana produksinya untuk memenuhi permintaan dari lembaga-lembaga pendidikan yang ada di bawah naungan Pesantren Tebuireng. Dan konveksi Tebuireng juga menerima pesanan pembuatan berbagai pakaian dari pihak luar. Disini pihak konveksi dituntut untuk menghasilkan produk yang berkualitas baik, untuk itu perlu diterapkan teknik pengembangan kualitas dalam proses produksi.

Dalam perjalanan produksinya konveksi Tebuireng tidak lepas dari adanya penyimpangan penjahitan yang menyebabkan produk-produk yang dihasilkan tidak sesuai dengan standar dan spesifikasi produk yang diinginkan. Dimana produk hasil jahitan mengalami kecacatan atau defect yang dapat menyebabkan terjadinya penurunan kualitas hasil produksi. Hal ini akan merugikan bagi konveksi karena dapat mengurangi kepuasan yang didapat konsumen, dan lebih lanjut akan mengakibatkan konveksi dapat kehilangan konsumen.

Untuk itu salah satu metode yang dapat membantu meningkatkan kualitas produk dengan berusaha untuk mengurangi kecacatan yang terjadi adalah dengan menerapkan Metode Six Sigma. Six sigma dapat dijadikan ukuran kinerja sistem industri yang memungkinkan perusahaan melakukan peningkatan yang luar biasa dengan terobosan strategi yang aktual. Six sigma juga dapat dipandang sebagai pengendalian proses industri yang berfokus pada pelanggan dengan memperhatikan kemampuan proses (Ama Lusiana, 2007:3).

Berdasarkan penjelasan di atas, rumusan masalah yang diambil adalah mengetahui apa saja faktorfaktor penyebab defect menggunakan metode six sigma, menghitung nilai sigma kualitasnya, serta usulan tindakan apa yang harus dilakaukan oleh pihak konveksi.

\section{METODE}

Penelitian ini menggunakan metode Six Sigma dengan konsep DMAIC (Define, Measure, Analyze, Improve, Control) dilakukan di Tempat Praktik Keterampilan Usaha (TPKU) konveksi Tebuireng yang letaknya berada tepat di depan komplek Pondok Pesantren Putri Tebuireng, Jl. Irian Jaya, Cukir, Diwek Kabupaten Jombang. Objek yang menjadi penelitian adalah produk seragam sekolah yang mengalami kecacatan atau ketidaksesuaian dari hasil produksi konveksi Tebuireng. Kemudian langkah-langkah penelitian yang akan dilakukan adalah sebagai berikut :

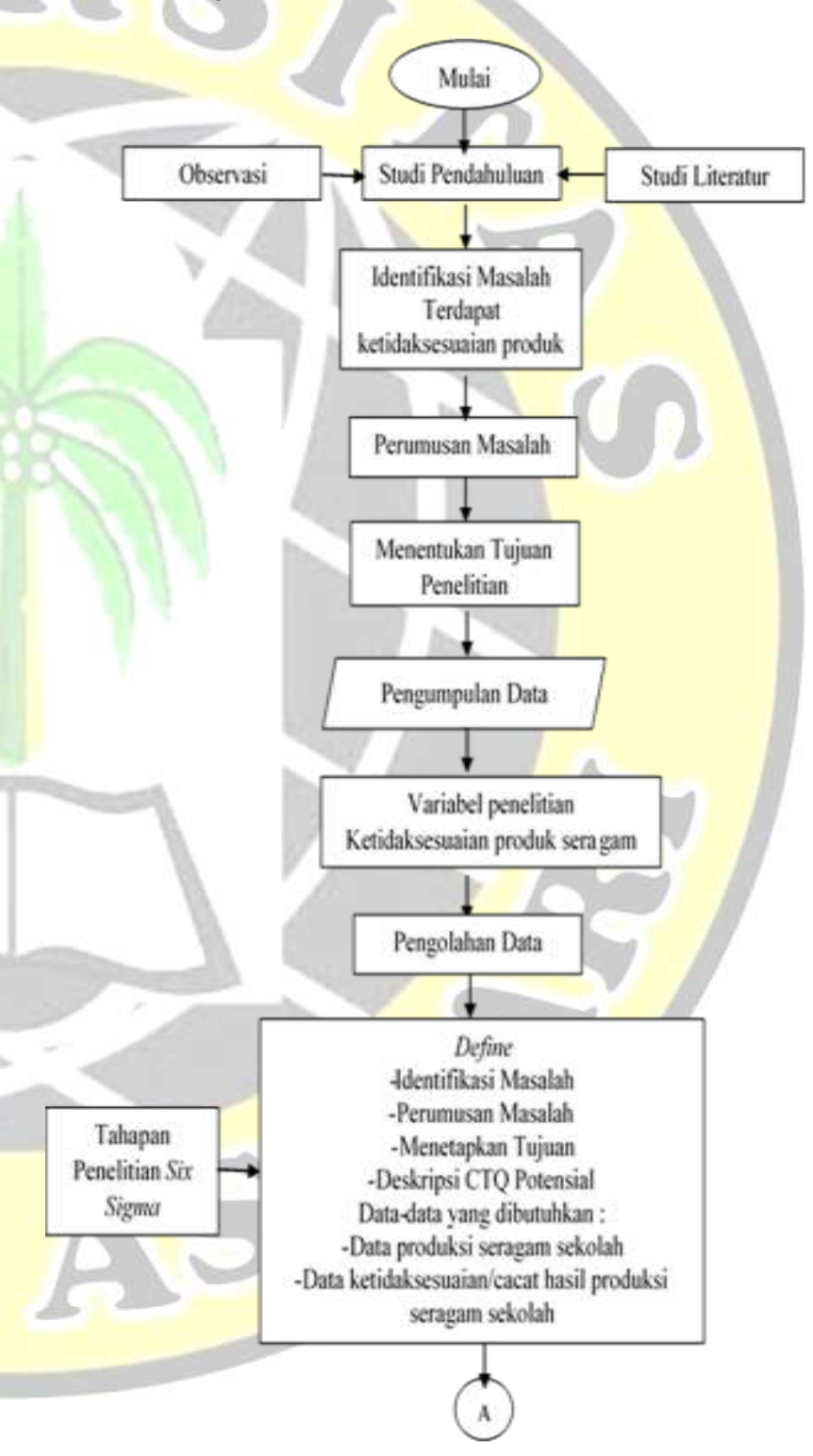




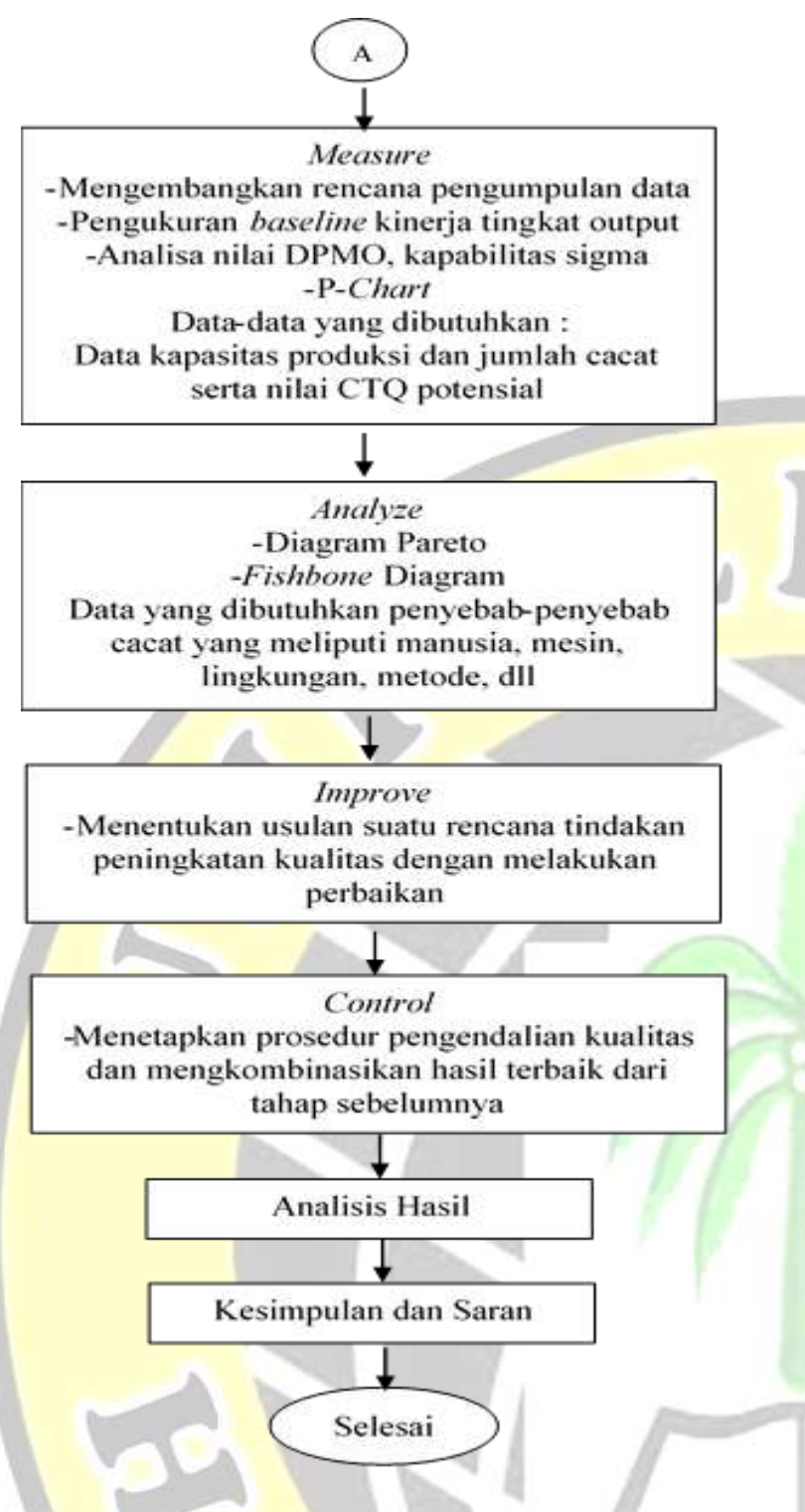

Gambar 1. Langkah-Langkah Penelitian di TPKU Konveksi Tebuireng

Pengolahan data yang dilakukan dalam penelitian ini melalui bebrapa fase, yaitu :

\section{Fase Define}

Pada fase ini dilakukan identifikasi masalah yang terjadi di dalam konveksi Tebuireng. Serta menentukan data-data yang akan dibutuhkan dalam penelitian.

\section{Fase Measure}

Fase ini dilakukan pengukuran baseline kinerja dengan menggunakan parameter DPMO kemudian menentukan nilai Sigma dan menggunakan P-Chart untuk mengetahui apakah cacat produk yang ada masih dalam batas kendali atau tidak.

Rumus menghitung nilai rata-rata total proporsi produk cacat :

$$
P=\operatorname{\Sigma np} / \Sigma n
$$

Dimana : $\quad \mathrm{n}=$ Jumlah Sampel

$\mathrm{np}=$ Jumlah Kecacatan

$p=$ Rata-rata proporsi kecacatan

Rumus menghitung nilai Batas Kendali Atas (UCL) dan Batas Kendali Bawah (LCL) :

$$
U C L=p+3 \sqrt{\frac{p(1-p)}{n}}
$$

\section{Fase Analyze}

Fase ini akan dilakukan sebuah analisis sebab utama yang menyebabkan masalah atau faktorfaktor terhadap penyebab terjadinya cacat menggunakan diagram sebab akibat. Kemudian mengurutkan cacat produk dari yang sering terjadi hingga cacat produk yang terjadi dengan menggunakan diagram pareto.

\section{Fase Improve}

Fase Improve berisi usulan tindakan yang harus dilakukan konveksi untuk mengurangi terjadinya cacat produk seragam sekolah sesuai dengan data yang didapat dari diagram sebab akibat.

\section{Fase Control}

Fase Control berisi tindakan pengawasan dan pengontrolan yang perlu dilakukan sesuai dengan tahapan perbaikan pada fase sebelumnya.

\section{HASIL DAN PEMBAHASAN}

Pengambilan sampel data pada konveksi dimulai pada bulan Mei 2018 sampai Juni 2018 selama 6 minggu. Selama 6 minggu tersebut akan dilakukan pemeriksaan sebanyak 24 kali. Sampel yang akan diperiksa yaitu seragam sekolah yang akan diambil dari jumlah populasi hasil produksi sebanyak 2.100 jahitan. Untuk menentukan seberapa banyak sampel yang harus diambil untuk diperiksa dari total populasinya menggunakan rumus Slovin (Sevilla, Consuelo G. Et. al, 2007).

$$
n=\frac{N}{1+\mathrm{Ne}^{2}}
$$

Dimana : $\quad \mathrm{n}=$ Jumlah sampel

$\mathrm{N}=$ Jumlah Populasi

$$
\mathrm{e}=\text { Batas toleransi kesalahan }
$$

Untuk batas toleransi yang dipakai disini menggunakan 0,05. Sehingga dengan menggunakan rumus diatas dapat dihitung jumlah minimal sampel yang harus diperiksa dari total populasinya yang sebesar 2.100 adalah sebanyak 336 sampel produk.

Setelah diketahui semua data-data yang diperlukan, selanjutnya akan dilakukan pengolahan dan analisis menggunakan metode six sigma melalui 5 fase atau tahapan, yang dimulai dari fase define, 
measure, analyze, improve, dan control. Penjelasan dari tahapan-tahapan yang ada adalah sebagai berikut :

\section{Fase Define}

Pada fase Define merupakan tahap pendefinisian masalah kualitas yang terjadi pada Konveksi Tebuireng. Pada tahap ini akan mendefinisikan apa yang menjadi penyebab dari terjadinya cacat produk seragam sekolah. Berdasarkan atas permasalahan yang terjadi di konveksi, terdapat karakteristik atau Critical to Quality yang sering terjadi pada TPKU/Konveksi Tebuireng, yakni:

Tabel 2. Jenis Ketidaksesuaian Prooduk Seragam

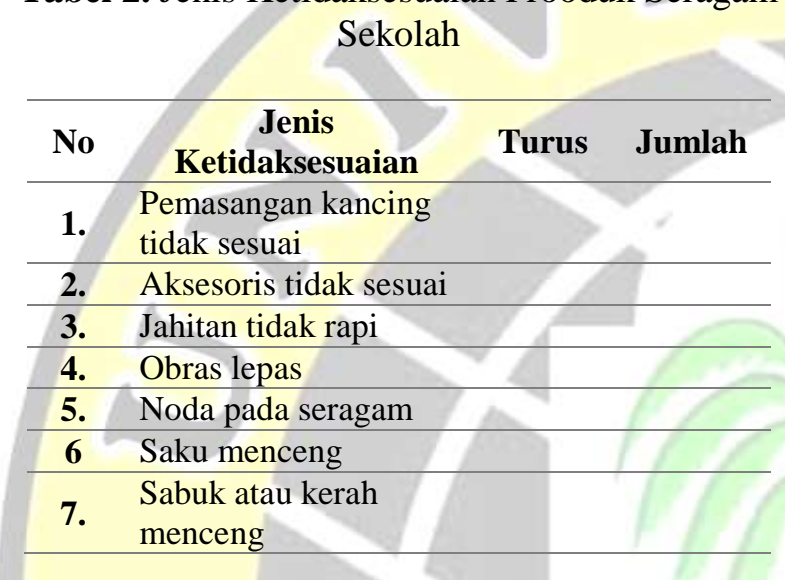

Dari tabel di atas diketahui bahwa ada 7 jenis kecacatan pada produk seragam sekolah yang sering terjadi.

\section{Fase Measure}

Setelah dilakukan pendefinisian masalah yang akan dianalisis, kemudian akan dilakukan pengelompokkan dan penjumlahan cacat atau ketidaksesuaian produk sesuai dengan CTQ yang ada. Dalam mengumpulkan seberapa banyak cacat yang terjadi penulis menggunakan alat bantu check sheet. Berikut akan dijelaskan berdasarkan Tabel:
Tabel 3. Jumlah Data Ketidaksesuaian/Cacat Produk Seragam Sekolah

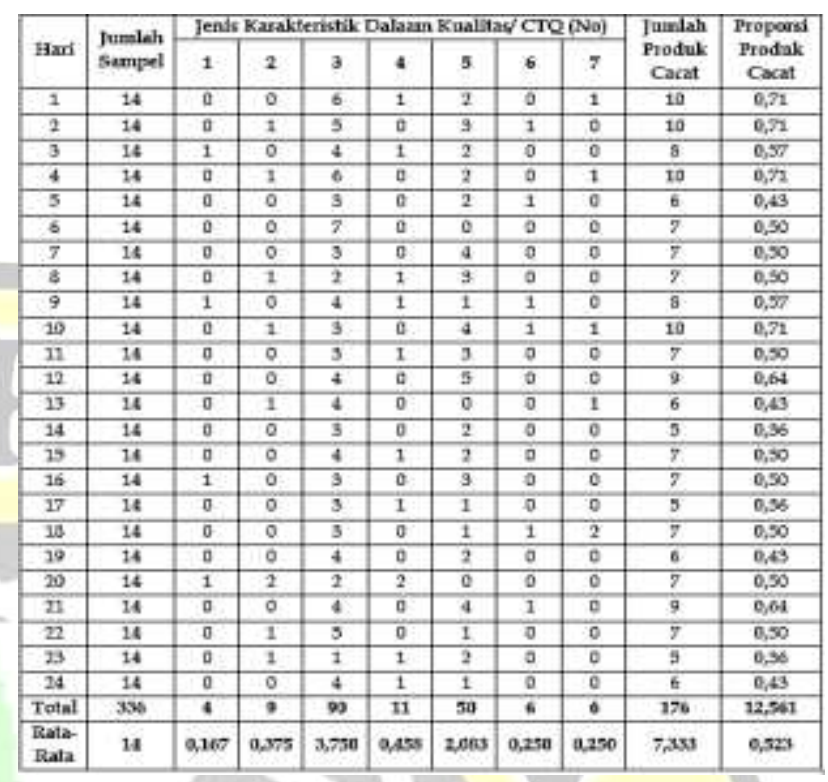

Dari tabel diketahui, bahwa jumlah kecacatan yang paling sering terjadi disebabkan oleh jenis CTQ nomor 3 dan 5, yaitu jahitan tidak rapi serta noda pada seragam. Total jumlah cacat yang disebabkan karena jahitan tidak rapi sebanyak 90 produk, dan yang disebabkan karena adanya noda pada seragam sebanyak 50 produk. Karena kedua jenis CTQ ini yang paling dominan sering terjadi, maka penulis hanya akan memfokuskan pengamatannya pada kedua jenis CTQ tersebut. Serta diketahui pula jumlah proporsi produk cacat sebesar 12,561.

Ada dua langkah perhitungan pada fase ini,

a. Analisis diagram P-Chart

Diagram ini berfungsi untuk mengetahui apakah kecacatan pada produk masih dalah batas kendali atau tidak. Untuk itu perlu dicari nilai rata-rata total proporsi produk cacat dan batas kendali atas bawahnya.

$$
\begin{aligned}
& p=\frac{12,561}{24}=0,523 \\
& U C L=0,523+3 \sqrt{\frac{0,523(1-0,523)}{14}}=0,923 \\
& L C L=0,523-3 \sqrt{\frac{0,523(1-0,523)}{14}}=0,123
\end{aligned}
$$


Tabel 4. Hasil perhitungan UCL dan LCL

\begin{tabular}{|c|c|c|c|c|c|c|}
\hline Hari & $\begin{array}{c}\text { Jumlah } \\
\text { Sampel }\end{array}$ & $\begin{array}{c}\text { Jumlah } \\
\text { Produk } \\
\text { Cacat }\end{array}$ & $\begin{array}{c}\text { Proporsi } \\
\text { Produk } \\
\text { Cacat }\end{array}$ & $\boldsymbol{P}$ & UCL & LCL \\
\hline 1 & 14 & 10 & 0,71 & 0,523 & 0,923 & 0,123 \\
\hline 2 & 14 & 10 & 0,71 & 0,523 & 0,923 & 0,123 \\
\hline 3 & 14 & 8 & 0,57 & 0,523 & 0,923 & 0,123 \\
\hline 4 & 14 & 10 & 0,71 & 0,523 & 0,923 & 0,123 \\
\hline 5 & 14 & 6 & 0,43 & 0,523 & 0,923 & 0,123 \\
\hline 6 & 14 & 7 & 0,50 & 0,523 & 0,923 & 0,123 \\
\hline 7 & 14 & 7 & 0,50 & 0,523 & 0,923 & 0,123 \\
\hline 8 & 14 & 7 & 0,50 & 0,523 & 0,923 & 0,123 \\
\hline 9 & 14 & 8 & 0,57 & 0,523 & 0,923 & 0,123 \\
\hline 10 & 14 & 10 & 0,71 & 0,523 & 0,923 & 0,123 \\
\hline 11 & 14 & 7 & 0,50 & 0,523 & 0,923 & 0,123 \\
\hline 12 & 14 & 9 & 0,64 & 0,523 & 0,923 & 0,123 \\
\hline 13 & 14 & 6 & 0,43 & 0,523 & 0,923 & 0,123 \\
\hline 14 & 14 & 5 & 0,36 & 0,523 & 0,923 & 0,123 \\
\hline 15 & 14 & 7 & 0,50 & 0,523 & 0,923 & 0,123 \\
\hline 16 & 14 & 7 & 0,50 & 0,523 & 0,923 & 0,123 \\
\hline 17 & 14 & 5 & 0,36 & 0,523 & 0,923 & 0,123 \\
\hline 18 & 14 & 7 & 0,50 & 0,523 & 0,923 & 0,123 \\
\hline 19 & 14 & 6 & 0,43 & 0,523 & 0,923 & 0,123 \\
\hline 20 & 14 & 7 & 0,50 & 0,523 & 0,923 & 0,123 \\
\hline 21 & 14 & 9 & 0,64 & 0,523 & 0,923 & 0,123 \\
\hline 22 & 14 & 7 & 0,50 & 0,523 & 0,923 & 0,123 \\
\hline 23 & 14 & 5 & 0,36 & 0,523 & 0,923 & 0,123 \\
\hline 24 & 14 & 6 & 0,43 & 0,523 & 0,923 & 0,123 \\
\hline Total & 336 & $\mathbf{1 7 6}$ & $\mathbf{1 2 , 5 6 1}$ & & & \\
\hline $\begin{array}{l}\text { Rata- } \\
\text { Rata }\end{array}$ & $\mathbf{1 4}$ & $\mathbf{7 , 3 3 3}$ & $\mathbf{0 , 5 2 3}$ & & & \\
\hline & & & & & & \\
\hline
\end{tabular}

Dari tabel tersebut selanjutnya akan dirubah kedalam bentuk diagram P-Chart sebagai berikut :

Kapabilitas Proses

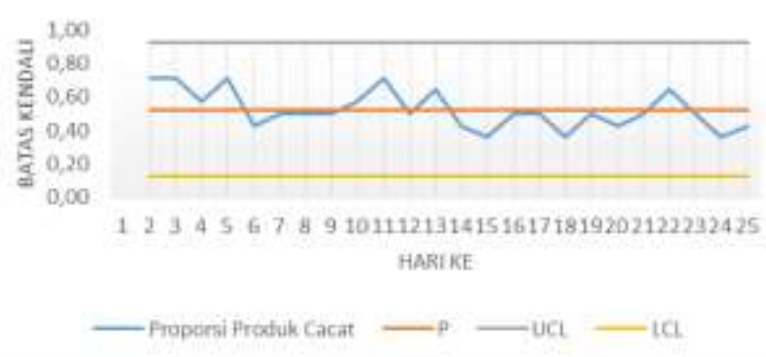

Gambar 2. Peta Kendali Cacat Produk

Dari diagram tersebut diketahui bahwa cacat produk masih dalam batas kendali perusahaan, karena proporsi produk cacatnya tidak melewati kedua batas kendali yang ada.

b. Mengukur nilai tingkat sigma dan nilai DPMO

Dibawah ini akan dijelaskan mengenai hasil perhitungan nilai sigma dan DPMO.
Tabel 5. Nilai Sigma dan Nilai DPMO

\begin{tabular}{|c|c|c|c|c|c|c|}
\hline Hari & $\begin{array}{l}\text { Jumlah } \\
\text { Sampel }\end{array}$ & $\begin{array}{l}\text { Jumlah } \\
\text { Produk } \\
\text { Cacat }\end{array}$ & $\begin{array}{c}\text { Banyak } \\
\text { CIQ }\end{array}$ & Proporsi & DPMO & Sigma \\
\hline 1 & 14 & 10 & 7 & 0,71 & 102041 & 2,73 \\
\hline 2 & 14 & 10 & 7 & 0,71 & 102041 & 2,73 \\
\hline 3 & 14 & 8 & 7 & 0,57 & 81633 & 2,90 \\
\hline 4 & 14 & 10 & 7 & 0,71 & 102041 & 2,78 \\
\hline 5 & 14 & 6 & 7 & 0,43 & 61224 & 3,05 \\
\hline 6 & 14 & 7 & 7 & 0,50 & 71429 & 2,97 \\
\hline 7 & 14 & 7 & 7 & 0,50 & 71429 & 2,97 \\
\hline 8 & 14 & 7 & 7 & 0,50 & 7429 & 2,97 \\
\hline 9 & 14 & 8 & 7 & 0,57 & 81633 & 2,90 \\
\hline 10 & 14 & 10 & 7 & 0,71 & 102041 & 2,73 \\
\hline 11 & 14 & 7 & 7 & 0,50 & 71429 & 2,97 \\
\hline 12 & 14 & 9 & 7 & 0,64 & 91837 & 2,83 \\
\hline 13 & 14 & 6 & 7 & 0,43 & 61224 & 3,05 \\
\hline 14 & 14 & 5 & 7 & 0,36 & 51020 & 3,14 \\
\hline 15 & 14 & 7 & 7 & 0,50 & 71429 & 2,97 \\
\hline 16 & 14 & 7 & 7 & 0,50 & 74429 & 2,97 \\
\hline 17 & 14 & 5 & 7 & 0,36 & 51020 & 3,14 \\
\hline 18 & 14 & 7 & 7 & 0,50 & 7429 & 2,97 \\
\hline 19 & 14 & 6 & 7 & 0,43 & 61224 & 3,05 \\
\hline 20 & 14 & 7 & 7 & 0,50 & 71429 & 2,97 \\
\hline 21 & 14 & 9 & 7 & 0,64 & 91837 & 2,83 \\
\hline 22 & 14 & 7 & 7 & 0,50 & 71429 & 2,97 \\
\hline 23 & 14 & 5 & 7 & 0,36 & 51020 & 3,14 \\
\hline 24 & 14 & 6 & 7 & 0,43 & 61224 & 3,05 \\
\hline Total & 336 & 176 & & 12,561 & & \\
\hline $\begin{array}{l}\text { Rata- } \\
\text { Rata }\end{array}$ & 14 & 7 & 7 & 0,523 & 74830 & 2,95 \\
\hline
\end{tabular}

Dari tabel diketahui bahwa jumlah sampel sebanyak 336 dan jumlah produk cacat sebanyak 176. Kemudian nilai rata-rata proporsinya adalah sebesar 0,523 , dan nilai DPMO nya adalah 74.830 produk. Dari nilai DPMO tersebut dapat diketahui bahwa nilai sigmanya berada pada tingkatan 29,5 . Hal ini dapat diartikan bahwa apabila perusahaan memproduksi seragam sekolah sebanyak 1.000.000 produk maka produk yang mengalami kecacatan masih sangat besar yaitu sebesar 74.830 produk.

\section{Fase Analyze}

a. Diagram Pareto

Untuk mengetahui jenis CTQ yang paling dominan maka perlu menghitung persentase dari setiap jenis kecacatan tersebut. Rumus yang digunakan adalah sebagai berikut :

\% Kerusakan $=\frac{\text { Jumlah Kerusakan Jenis }}{\text { Jumlah Kerusakan Keseluruhan }} \times 100 \%$

Dengan menggunakan rumus diatas diketahui bahwa persentase kecacatan untuk jenis pemasangan kancing tidak sesuai sebesar $2,3 \%$, aksesoris tidak sesuai sebesar $5,1 \%$, jahitan tidak rapi sebesar $51,1 \%$, obras lepas sebesar $6,3 \%$, noda pada seragam sebesar $28,4 \%$, saku menceng sebesar $3,4 \%$, dan sabuk atau kerah menceng sebesar 3,4\%. Untuk itu akan dijelaskan pada diagram pareto di bawah ini : 


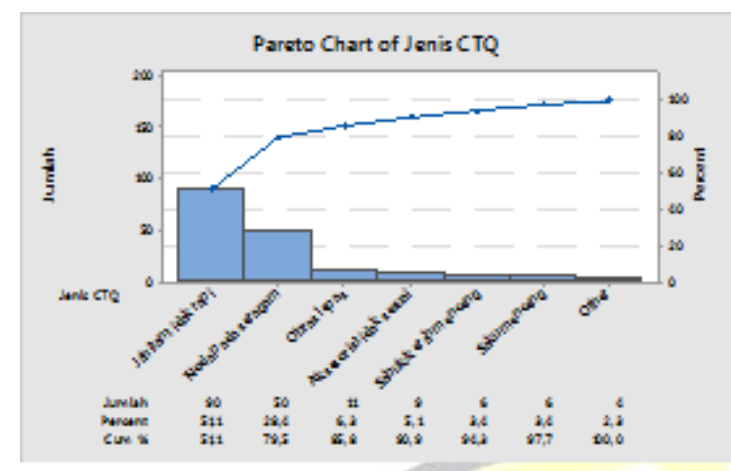

Gambar 2. Persentase Jenis CTQ

Dari gambar dapat di simpulkan bahwa jenis ketidaksesuaian yang paling dominan adalah jahitan tidak rapi dan noda pada seragam. Sehingga kedua jenis CTQ ini yang akan penulis bahas selanjutnya.

\section{b. Diagram Sebab Akibat}

Dengan menggunakan diagram sebab akibat kita dapat mengetahui faktor-faktor penyebab kecacatan dari kedua jenis CTQ tersebut dengan membuat pertanyaan terbuka kepada petugas konveksi yang paling memahami tentang hal ini. Dan beberapa faktor tersebut dapat digambarkan dengan diagram sebab akibat seperti Gambar dibawah ini :

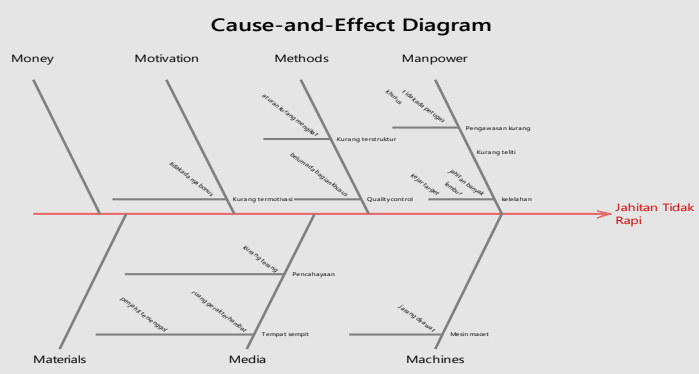

Gambar 3. Diagram Sebab Akibat untuk jahitan tidak rapi

Penyebab jahitan tidak rapi ada beberapa faktor, yakni:

1) Tenaga kerja

a) Sering lembur

b) Petugas kurang teliti

c) Belum ada pengawas khusus

2) Metode kerja

a) Peraturan kurang terstruktur

b) Quality control belum ada

3) Mesin

a) Mengalami macet

4) Media (Tempat dan Waktu Kerja)

a) Pencahayaan yang kurang

b) Tempat terlalu sempit

5) Motivasi

a) Kurangnya motivasi kerja

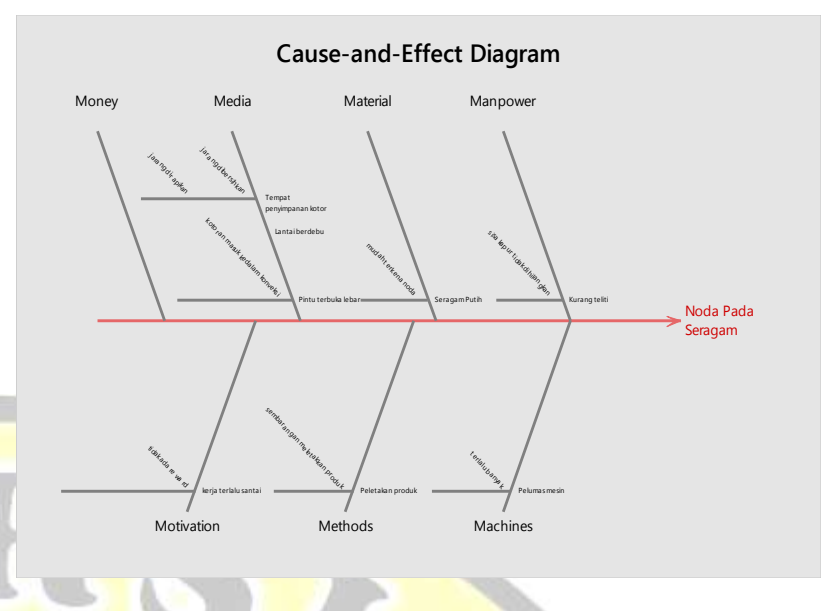

Gambar 4. Diagram Sebab Akibat Untuk Noda Pada Seragam

Penyebab noda pada seragam ada beberapa faktor, yakni :

1) Tenaga kerja

a) Kurang teliti

2) Material

a) Seragam putih

3) Mesin

a) Pelumas mesin

4) Media (Tempat dan Waktu Kerja)

a) Pintu terbuka lebar

b) Lantai produksi kotor

c) Lemari penyimpanan kotor

5) Metode

a) Cara peletakan barang

6) Motivasi

a) Motivasi kerja kurang

\section{Fase Improve}

Pada tahap ini diberikan usulan tindakan yang ditujukan kepada pihak konveksi sebagai salah satu cara untuk mengurangi terjadinya kecacatan produk berdasarkan penyebabnya yang diketahui dari diagram sebab akibat.

\section{1) Usulan tindakan untuk jenis cacat jahitan tidak rapi}

Usulan tindakan yang diberikan akan dijabarkan lebih jelasnya pada tabel di bawah ini : 
Tabel 6. Usulan Tindakan Kegiatan

\begin{tabular}{|c|c|c|c|}
\hline Unsw & Faktor Penyebab & Standar Perusahaan & Usulan Tindakan Perbaikan \\
\hline Manpower & $\begin{array}{l}\text { 1, Penjahit kurang } \\
\text { teliti pada sast } \\
\text { penjahitan } \\
\text { 2, Karyawan kelelahan } \\
\text { karena bekerja terlalu } \\
\text { lama } \\
\text { 3, Tidak adanya } \\
\text { pengawwasan khusus } \\
\text { terhadap hasil jahitan } \\
\text { produk }\end{array}$ & $\begin{array}{l}\text { 1, Karyawwan hanus } \\
\text { mengikuti prosedur } \\
\text { penjahitan yang telah } \\
\text { ditentukan oleh Konveksi } \\
\text { Tebuireng } \\
\text { 2. Memproduksi barang } \\
\text { sesuai dengan kapasitas } \\
\text { kemampuan karyaswan } \\
\text { 3, Atasan akan mengontrol } \\
\text { kinerja karyawan }\end{array}$ & $\begin{array}{l}\text { 1, Kegiatan mengobrol saat } \\
\text { menjahit harus dikurangi dan } \\
\text { dihindari } \\
\text { 2, Konreksi tidak membebani } \\
\text { pekerjaan yang terlalu berat } \\
\text { kepada karyawan dengan tidak } \\
\text { memberikan pekerjaan setelah } \\
\text { jam keja habis } \\
\text { 3, Menunjuk seorang karyawan } \\
\text { yang bertugas unuk mengontrol } \\
\text { kegiatan produksi }\end{array}$ \\
\hline Methods & $\begin{array}{l}\text { 1. Belum adanya } \\
\text { petugas yangs } \\
\text { mengontrol hualitas } \\
\text { hasil produks } \\
\text { 2. Aturan yang ada } \\
\text { belum sepenuhnya } \\
\text { dilakukan oleh } \\
\text { karyawan }\end{array}$ & $\begin{array}{l}\text { 1. Hanus ada petugas QC } \\
\text { 2, Mengikuti standar } \\
\text { aturan yang telah dibuat } \\
\text { perusahasan (konveksi) }\end{array}$ & $\begin{array}{l}\text { 1, Menunjuk karyawan yang } \\
\text { bertugas untuk menekontrol } \\
\text { kegiatan produksi } \\
\text { 2, Aturan yang ada harus } \\
\text { ditegaskan lagi/bahkan harus } \\
\text { ada sanksi bagi yang melanggar }\end{array}$ \\
\hline Machiness & $\begin{array}{l}\text { Mesin yang } \\
\text { digunakan untuk } \\
\text { menjahit mengalami } \\
\text { kerusakan atau macet } \\
\text { karens kurangnya } \\
\text { perarwatan }\end{array}$ & $\begin{array}{l}\text { Mengadakan perawatan } \\
\text { yang berskala }\end{array}$ & $\begin{array}{l}\text { Selalu melakukan pengecekan } \\
\text { terhadap komponen mesin } \\
\text { sesuai dengan jadwal yang } \\
\text { ditentukar }\end{array}$ \\
\hline Media & $\begin{array}{l}\text { 1, terganggunya } \\
\text { penglihstan karyaswan } \\
\text { akbibat pencahayaan } \\
\text { yang kurang } \\
\text { 2, Ruang gerak yang } \\
\text { sempit serta } \\
\text { tergangounya } \\
\text { karyagwan saat proses } \\
\text { penjehitan }\end{array}$ & $\begin{array}{l}\text { 1, Mengatur pencahayaan } \\
\text { yang sesuai dengan } \\
\text { standar ruangan kerja } \\
\text { 2, Ruangan produksi yang } \\
\text { nyaman }\end{array}$ & $\begin{array}{l}\text { 1, Memberikan fasilitas yang } \\
\text { baik guna menurjang } \\
\text { pencahyyaan nuang yang tepat. } \\
2, \text { Memfasilitasi meja jahit yang } \\
\text { nyaman, serta menyusun tempat } \\
\text { produksi agar tidak tergangou } \\
\text { dengan kegiatan yang lainnya }\end{array}$ \\
\hline Motivabon & $\begin{array}{l}\text { Kurangnyal motivasi } \\
\text { untuk bekeja dengan } \\
\text { lebih baik }\end{array}$ & $\begin{array}{l}\text { Pemberian motivasi } \\
\text { kepada pegatwai secara } \\
\text { rutin }\end{array}$ & $\begin{array}{l}\text { Salah satu cara memberikan } \\
\text { motivasi kepada para pegarwai } \\
\text { agar bekerja dengan semangat } \\
\text { adalah dengan memberikan } \\
\text { bomus kepada karyawan yang } \\
\text { bekejja dengan sangat baik. }\end{array}$ \\
\hline
\end{tabular}

2) Usulan tindakan untuk jenis cacat noda pada seragam

Usulan tindakan yang diberikan akan dijabarkan lebih jelasnya pada tabel di bawah ini :

Tabel 7. Usulan Tindakan Kegiatan

\begin{tabular}{|c|c|c|c|}
\hline Unsur & Faktor Penyebab & Standar Perusahaan & $\begin{array}{c}\text { Usalan Tindakan } \\
\text { Ferbaikan }\end{array}$ \\
\hline Manpprser & $\begin{array}{l}\text { Bekas goresan kapur } \\
\text { yang tidak } \\
\text { dihilangken }\end{array}$ & $\begin{array}{l}\text { Menggunakan kapur } \\
\text { jahit seperlunya }\end{array}$ & $\begin{array}{l}\text { Menghilangkan belkas } \\
\text { kapur pada saat proses } \\
\text { peryetriksan. }\end{array}$ \\
\hline Materials & $\begin{array}{l}\text { Kain putih yang } \\
\text { mudah terkens noda }\end{array}$ & $\begin{array}{l}\text { Memaksi standar } \\
\text { kain yang sesuai }\end{array}$ & $\begin{array}{l}\text { Memastikan meja jahit } \\
\text { bersih dari kotoraan agar } \\
\text { tidak mengenai kain. }\end{array}$ \\
\hline Machiness & $\begin{array}{l}\text { Pelumas mesin yang } \\
\text { terlalu banyak }\end{array}$ & $\begin{array}{l}\text { Memberikan pelumas } \\
\text { mesin sesuai standar }\end{array}$ & $\begin{array}{l}\text { Memastikan pelumas yang } \\
\text { ada pada mesin tidak } \\
\text { menyebar kemana-mana }\end{array}$ \\
\hline Media & $\begin{array}{l}\text { Ruangan produksi } \\
\text { terlalu kotor karens } \\
\text { deba }\end{array}$ & $\begin{array}{l}\text { Menjaga ruangen } \\
\text { agar tetap bersih }\end{array}$ & $\begin{array}{l}\text { Membersibkan konvelsi } \\
\text { setiap hari, mengelap } \\
\text { lemari penyinganan dil. }\end{array}$ \\
\hline Methods & $\begin{array}{l}\text { Metode dalam } \\
\text { peletakan produk } \\
\text { yang telah selesai } \\
\text { dilakukan secara } \\
\text { semharangan }\end{array}$ & $\begin{array}{l}\text { Peletakan produk } \\
\text { yang telah selesai } \\
\text { dijahit diletakkan } \\
\text { pada rak } \\
\text { penyimpanan }\end{array}$ & $\begin{array}{l}\text { Perlu adanya peraturan } \\
\text { yang berlaku dalam bekerja } \\
\text { salah satunya yang } \\
\text { berkenaan dengan masalah } \\
\text { peletakan produk yeng } \\
\text { telah jadi poda tempat } \\
\text { yang seharusnya }\end{array}$ \\
\hline Motivation & $\begin{array}{l}\text { Tidak adarya maund } \\
\text { kepada karyawan } \\
\text { menyebabkamnys } \\
\text { bekerja terlalu sartai }\end{array}$ & $\begin{array}{l}\text { Pemberian rauur's } \\
\text { kepada karyansan } \\
\text { yang berprestasi }\end{array}$ & $\begin{array}{l}\text { Periu adanya pemberian } \\
\text { reward kepada karyawan- } \\
\text { karyawan yang telah tekur } \\
\text { dan giat dalam bekerja }\end{array}$ \\
\hline
\end{tabular}

Itulah beberapa usulan tindakan yang diberikan kepada pihak konveksi sesuai dengan data yang ada.

\section{Fase Control}

Tindakan pengontrolan yang dilakukan pada tahap ini secara umum akan dijelaskan sebagai berikut:

1) Mengawasi seluruh elemen yang ada didalam proses produksi.

2) Melakukan pengawasan terhadap bahan baku dan karyawan bagian produksi agar mutu barang yang dihasilkan lebih baik.

3) Menegaskan kembali standar kerja kepada seluruh karyawan Konveksi Tebuireng.

4) Mengurangi beban kerja terhadap karyawan sesuai dengan kapasitas kemampuan yang dimiliki konveksi.

5) Melakukan pencatatan atas seluruh produk catat setiap hari dari masing-masing jenis dan mesin, yang dilakukan oleh karyawan dalam proses produksi.

6) Mengangkat karyawan yang khusus mengawasi seluruh proses kegiatan yang ada.

7) Total produk cacat dalam periode satu bulan yang telah dicatat dilaporkan keatasan yang bertanggungjawab.

8) Melakukan evaluasi serta meningkatkan tindakan perbaikan kualitas secara terus menerus.

\section{KESIMPULAN}

Berdasarkan hasil dan pembahasan maka diperoleh kesimpulan sebagai berikut :

1. Pada hasil produksi Konveksi Tebuireng berupa seragam sekolah pada bulan Mei 2018 hingga pertengahan Juni 2018 (6 minggu) terdapat 7 jenis ketidaksesuaian atau kecacatan yang sering terjadi. 7 jenis ketidaksesuaian tersebut antara lain adalah:

1) Pemasangan kancing tidak sesuai

2) Aksesoris tidak sesuai

3) Jahitan tidak rapi

4) Obras lepas

5) Noda pada seragam

6) Saku menceng

7) Sabuk atau kerah menceng

Dari ke 7 jenis defect atau cacat tersebut terdapat 2 jenis cacat yang paling dominan diantaranya adalah karena jahitan tidak rapi dan terdapat noda pada seragam dengan masing-masing persentase kecacatan sebesar $51,1 \%$ dan $28,4 \%$.

2. Hasil dari 336 jumlah sampel seragam sekolah yang diambil untuk dilakukan pengecekan, terdapat 176 unit sampel yang mengalami masalah kecacatan. Dari data tersebut didapat 
nilai DPMO nya sebesar 74.830 dengan memiliki nilai sigma pada level tingkatan 2,95 sigma. Hal ini dapat diartikan bahwa dari 1.000.000 produk yang dihasilkan terdapat 74.830 produk yang cacat, sedangkan sisanya yaitu produk yang tidak mengalami kecacatan sebanyak 925.170 produk.

3. Langkah yang harus dilakukan oleh konveksi untuk mengurangi tingkat kecacatan produk yang sering terjadi adalah dengan memfokuskan pengawasannya untuk memperbaiki kinerja karyawan, kinerja mesin, standar kerja yang berlaku, sarana dan prasarana yang ada, memberikan motivasi dalam bekerja, serta memperbaiki manajemen waktu dengan baik.

\section{SARAN}

Berdasarkan kesimpulan yang telah diperoleh, maka penulis ingin memberikan saran kepada perusahaan dan peneliti lain yang ingin melakukan penelitian dibidang yang sama, antara lain:

1. Penelitian ini belum sempurna, karena pada tahapan improve masih berupa usulan tindakan yang diberikan peneliti kepada pihak Konveksi Tebuireng, dan pada tahapan control masih berupa kumpulan tindakan yang umum dilakukan sebagai bentuk penerapan dari tahapan improve yang belum tentu diterima dan diterapkan oleh pihak konveksi. Maka untuk kebutuhan penelitian selanjutnya bagi yang berminat meneliti tentang pengendalian kualitas menggunakan metode six sigma diharapkan dapat memberikan usulan tindakan perbaikannya kepada Konveksi Tebuireng sehingga pihak konveksi mau menerima dan melaksanakan usulan tersebut.

2. Diharapkan dengan adanya penelitian ini bisa menjadi rujukan kajian sains sehingga dapat membantu dalam kegiatan civitas akademik serta dapat berkontribusi dalam bidang ilmu pendidikan dan ilmu terapan terutama ilmu teknik industri.

\section{DAFTAR PUSTAKA}

Lusiana, Ama. 2007. Analisis Pengendalian Kualitas Produk Dengan Menggunakan Metode Six Sigma Pada PT. Sandang Nusantara Unit Patal Secang. Akuntansi. Fakultas Ekonomi. Universitas Negeri Semarang.

Putra, Roy. 2016. Analisis Pengendalian Proses Dalam Upaya Meningkatkan Kualitas Produk Dengan Menggunakan Metode Six Sigma (Studi Kasus Pada Koncoveksi). Teknik Industri.
Fakultas Teknologi Industri. Universitas Islam Indonesia. Yogyakarta.

Sevilla, Consuelo G. et. al (2007). "Research Methods". Rex Printing Company. QuezonCity.

Tjiptono, Fandy, Anastasia Diana. 2001. Total Quality Management. Yogyakarta: Andi.

Wignjosoebroto, Sritomo. 2003. Pengantar Teknik Manajemen Industri. Surabaya: Guna Widya. 